\title{
Aclimatação ao frio e dano por geada em canola
}

\author{
Genei Antonio Dalmago(1), Gilberto Rocca da Cunha( ${ }^{(1)}$, Anderson Santi( ${ }^{(1)}$, João Leonardo Fernandes Pires ${ }^{(1)}$, \\ Alexandre Luiz Müller(2) e Laise Maria Bolis(2)
}

\begin{abstract}
(1)Embrapa Trigo, Caixa Postal 451, CEP 99001-970 Passo Fundo, RS. E-mail: dalmago@cnpt.embrapa.br, cunha@cnpt.embrapa.br, anderson@cnpt.embrapa.br, pires@cnpt.embrapa.br (2)Universidade de Passo Fundo, BR 285, Km 171, Bairro São José, CEP $99001-970$ Passo Fundo, RS. E-mail: ale.muller@hotmail.com, laisebolis46@yahoo.com.br
\end{abstract}

Resumo - O objetivo deste trabalho foi avaliar a influência da aclimatação ao frio sobre o dano causado pela geada em diferentes estádios fenológicos de genótipos de canola. Foram realizados cinco experimentos em ambiente controlado, em 2006, 2007 e 2008. Os fatores avaliados foram: genótipos, aclimatação (com; sem), intensidades de geada, estádios de desenvolvimento de plantas, regimes de aclimatação e regimes de geada. As variáveis avaliadas foram: queima de folhas, massa de matéria seca, estatura de plantas, duração de subperíodo, componentes de rendimento e rendimento de grãos. A aclimatação ao frio, antes da geada, resultou em menor queima de folhas e maior massa de matéria seca, em comparação a plantas não aclimatadas. As geadas foram prejudiciais a partir de $-6^{\circ} \mathrm{C}$ no início do ciclo de desenvolvimento, principalmente em plantas não aclimatadas, e a partir de $-4^{\circ} \mathrm{C}$ na floração, com redução do número de síliquas e do número de grãos por síliqua. A aclimatação após as geadas não contribuiu para a tolerância da canola a esse evento. Geadas consecutivas não acarretaram maior prejuízo à canola. A aclimatação de plantas de canola antes da geada reduz os danos, principalmente quando a geada ocorre no início do desenvolvimento das plantas.

Termos para indexação: Brassica napus, estresse térmico, temperatura baixa, tolerância ao frio.

\section{Acclimatization to cold and frost-injury in canola}

\begin{abstract}
The objective of this work was to evaluate the influence of cold acclimatization on frost damage at different phenological stages of canola genotypes. Five experiments were carried out under controlled conditions, in 2006, 2007, and 2008. The evaluated factors were: genotypes, acclimatization (with; without), frost gradient, plant developmental stages, acclimatization regimes and frost regimes. The evaluated variables were: leaf scorching symptoms, dry weight, plant height, length of subperiod, yield components and grain yield. The acclimatization before frost resulted in lesser leaf scorching symptoms and higher dry matter in comparison to plants not acclimated. Frosts were harmful from $-6^{\circ} \mathrm{C}$ in early plant development stage, mainly in nonacclimated plants, and from $-4^{\circ} \mathrm{C}$ at flowering, reducing the number of pods and the number of grains per pod. Acclimatization after frost did not contribute to the tolerance of canola to frost. Consecutive frosts caused no greater impairment to canola. The canola acclimatization before frost reduces damage caused by it, mainly when the frost occur in the initial plant development stages.
\end{abstract}

Index terms: Brassica napus, thermal stress, low temperature, tolerance to cold.

\section{Introdução}

A canola (Brassica napus L.) é uma espécie oleaginosa de clima frio. O cultivo comercial de canola no mundo concentra-se em regiões temperadas, principalmente em latitudes superiores a $35^{\circ}$ (McClinchey \& Kott, 2008). A temperatura do ar é a variável ambiental mais importante na regulação do crescimento e desenvolvimento da canola (Thomas, 2003). O valor ótimo de temperatura para o seu desenvolvimento é de cerca de $20^{\circ} \mathrm{C}$, com limites extremos entre 12 e $30^{\circ} \mathrm{C}$ (Robertson et al., 2002; Thomas, 2003). Essas condições térmicas são encontradas na maior parte da
Região Sul do Brasil, durante o outono, o inverno e no início da primavera, e correspondem ao período do ano em que se cultiva a canola no Rio Grande do Sul, Santa Catarina e Paraná. Todavia, neste período do ano, no Sul do Brasil, também é elevado o risco de ocorrência de geadas, que podem afetar negativamente a canola e comprometer o rendimento de grãos, a depender da intensidade e do estádio de desenvolvimento da cultura, além das condições ambientais prévias ao evento.

A geada prejudica a canola quando ocorre no início do ciclo de desenvolvimento das plantas e por ocasião do florescimento e do enchimento de

Pesq. agropec. bras., Brasília, v.45, n.9, p.933-943, set. 2010 
grãos (Robertson et al., 2002, 2004; McClinchey \& Kott, 2008). De maneira geral, a morte de plântulas é verificada com geada de -3 e $-4^{\circ} \mathrm{C}$, principalmente no estádio cotiledonar. Neste estádio, a sensibilidade às baixas temperaturas é maior do que quando as plantas possuem três a quatro folhas (Thomas, 2003). Gusta et al. (2004) observaram que, em plantas não aclimatadas e sob condições de baixas temperaturas, a morte de folhas é rápida a $-4,6^{\circ} \mathrm{C}$. Porém, plantas com cinco ou mais folhas, quando crescem em ambiente com temperatura média do ar inferior a $18^{\circ} \mathrm{C}$, podem resistir a geadas de $-8,6^{\circ} \mathrm{C}$ (Rapacz, 1999; Hawkins et al., 2002) e $-12^{\circ} \mathrm{C}$, no caso de canola de inverno (Rife \& Zeinali, 2003).

Durante o florescimento e o enchimento de grãos, a geada pode causar abortamento de flores e retenção de clorofila nos grãos, formando grãos verdes, que afetam negativamente a qualidade e a produção de grãos (Johnson-Flanagan et al., 1992; Thomas, 2003; McClinchey \& Kott, 2008). JinLing (1997) observou que baixas temperaturas do ar diminuem o número de grãos, em decorrência da redução da germinação dos grãos de pólen.

Para resistir às geadas, a canola deve passar por um período de aclimatação ao frio previamente à ocorrência delas. A aclimatação induz mudanças morfológicas, fisiológicas, bioquímicas e moleculares que tornam as plantas resistentes não somente a temperaturas congelantes, mas especialmente à desidratação provocada pelo congelamento (Rapacz, 1999; Hawkins et al., 2002; Gusta et al., 2004; Tasseva et al., 2004; Asghari et al., 2008; Stavang et al., 2008).

O processo de aclimatação é uma estratégia de proteção importante para que a planta suporte períodos de frio com ocorrência de geadas. Na Região Sul do Brasil, é comum a ocorrência de geadas extemporâneas e consecutivas, por vários dias seguidos, bem como de diferentes intensidades, sem que, antecipadamente, tenham sido registradas temperaturas do ar com potencial de aclimatação $\left(10\right.$ e $\left.15^{\circ} \mathrm{C}\right)$ (Rapacz, 1999; Rapacz et al., 2001; Rife \& Zeinali, 2003; Tasseva et al., 2004). Os efeitos de intensidades e condições de ocorrência de geadas em canola, bem como do grau de resposta à aclimatação das plantas ao frio, não são conhecidos, especialmente no caso dos genótipos atualmente indicados para cultivo no Brasil. Em razão do aumento da área ocupada por esta oleaginosa no
País, nos últimos anos, e do potencial de cultivo em novas áreas, como espécie alternativa de inverno nos sistemas de produção de grãos, é importante o conhecimento das respostas da canola ao frio e da influência da aclimatação nos efeitos ocasionados por geadas nesta cultura.

O objetivo deste trabalho foi avaliar as influências da aclimatação ao frio sobre o dano causado pela geada no início do ciclo de desenvolvimento e no momento da floração das plantas, em diferentes genótipos de canola indicados para cultivo no Brasil.

\section{Material e Métodos}

O trabalho foi realizado na Embrapa Trigo, em Passo Fundo, RS ( $28^{\circ} 15^{\prime} \mathrm{S}, 52^{\circ} 24^{\prime} \mathrm{W}$ e $687 \mathrm{~m}$ de altitude), e constituiu-se de cinco experimentos, dos quais três em 2006, experimento 1 a 3, um em 2007, experimento 4 e um em 2008, experimento 5.

Os experimentos foram realizados em casa de vegetação de vidro, de abril a junho, em 2006 e em 2007, e em câmara de crescimento, de janeiro a fevereiro, em 2008. Utilizou-se o delineamento experimental inteiramente casualizado, com arranjo fatorial. Nos períodos de realização dos experimentos, os valores dos principais elementos meteorológicos registrados - temperatura, umidade relativa e radiação solar -, estiveram próximos dos padrões normais para a região. Na média dos experimentos em casa de vegetação, registrou-se redução de $20 \%$ na radiação solar e aumentos de $1,5^{\circ} \mathrm{C}$ na temperatura e de $10 \%$ na umidade relativa do ar, em relação ao ambiente externo. As câmaras de crescimento apresentavam amplitude térmica de 0 a $50^{\circ} \mathrm{C}$, para aclimatação, e de -10 a $50^{\circ} \mathrm{C}\left( \pm 0,5^{\circ} \mathrm{C}\right)$, para simulação de geada, e intensidade máxima de luz de $1.225 \mu \mathrm{mol} \mathrm{m} \mathrm{m}^{-2} \mathrm{~s}^{-1}$.

A semeadura foi realizada em vasos de PVC com $0,5 \mathrm{~kg}$ de solo (unidade experimental), exceto no experimento 3 , em que os vasos tinham $10 \mathrm{~kg}$ de solo. O solo foi extraído do horizonte A de um Latossolo Vermelho distrófico típico, textura argilosa (Santos et al., 2006), e peneirado, homogeneizado e corrigido conforme análise química e indicação para a cultura (Tomm, 2007). Em cada vaso, foram colocadas dez sementes, tendo-se deixado três plantas nos experimentos 1 e 2, e quatro nos demais. A adubação e o controle fitossanitário foram realizados conforme as indicações para a cultura (Tomm, 2007). A irrigação foi 
feita diariamente, tendo-se mantido o teor de umidade do solo próximo ao da capacidade de campo, por meio da reposição do consumo de água.

A aclimatação foi feita de acordo com o objetivo de cada experimento, e consistiu em submeter as plantas a ciclos de temperatura e umidade do ar respectivamente de 12 a $2,5^{\circ} \mathrm{C}$ e 50 a $60 \%$, durante o dia, e de 9,5 a $2^{\circ} \mathrm{C}$ e 80 a $100 \%$, durante a noite, por três dias consecutivos, antes e depois da geada (Rife \& Zeinali, 2003). Para simular a geada, com temperatura do ar interna da câmara de crescimento entre 0 e $2,5^{\circ} \mathrm{C}$, as plantas foram umidificadas com água na mesma temperatura, com uso de um pulverizador, com a finalidade de estimular a formação de gelo sobre as plantas (Gusta et al., 2004; Silva et al., 2008). O regime de aclimatação foi baseado em Gusta et al. (2005), e as geadas foram definidas em estudo prévio de climatologia para o local (Silva et al., 2008).

O experimento 1 avaliou a aclimatação ao frio no desenvolvimento inicial da canola (três folhas). Os tratamentos foram os genótipos de canola Hyola 401, Hyola 43, Hyola 61, Hyola 420, Hyola 60, com e sem aclimatação, com seis repetições. No tratamento com aclimatação, $50 \%$ das plantas foram transferidas para a câmara de crescimento, para aclimatação, e as demais permaneceram na casa de vegetação, e foram para a câmara de crescimento no dia da geada, ou seja, sem aclimatação. A geada foi simulada no quarto dia após o início da aclimatação, com o emprego de ciclo térmico diário entre $9 \mathrm{e}-4^{\circ} \mathrm{C}$, tendo sido mantida a temperatura de $-4^{\circ} \mathrm{C}$ por uma hora. No dia seguinte à geada, as plantas aclimatadas retornaram à aclimatação por mais três dias, e as demais foram transferidas para a casa de vegetação.

$\mathrm{O}$ experimento 2 simulou intensidades de geada no desenvolvimento inicial da canola (três folhas). Os tratamentos foram os genótipos Hyola 401, Hyola 43, Hyola 61, Hyola 420, Hyola 60 e quatro intensidades de geada: sem geada e com geada leve, moderada e forte, a 2,5, 0, -3 e $-6^{\circ} \mathrm{C}$ (Silva et al., 2008), respectivamente, com três repetições. As geadas foram simuladas com ciclo térmico diário entre 9,5 e $-6^{\circ} \mathrm{C}$, tendo permanecido 1 hora em cada temperatura mínima. A simulação da geada foi similar à do experimento 1 , porém, neste caso, ao atingir a temperatura de $0^{\circ} \mathrm{C}$, o grupo de plantas referente a esse tratamento foi retirado da câmara de crescimento e transferido para uma câmara de crescimento auxiliar, que estava a $2,5^{\circ} \mathrm{C}$. O mesmo foi feito nas temperaturas de -3 e $-6^{\circ} \mathrm{C}$. As plantas permaneceram na câmara auxiliar até a temperatura do ar atingir $12^{\circ} \mathrm{C}$ (taxa de variação de $2^{\circ} \mathrm{C}$ por hora), quando foram transferidas para a casa de vegetação. Neste experimento, não foi realizada aclimatação.

No experimento 3, avaliou-se o efeito de geadas em diferentes estádios de desenvolvimento da canola. Os tratamentos foram os genótipos Hyola 401, Hyola 43, Hyola 61, Hyola 420 e Hyola 60 e cinco condições de geada: apenas aclimatação (A0), geada no início do ciclo (E1, 3 folhas), geada no período vegetativo (E2, 5 a 6 folhas), geada no início do florescimento (E3, 50\% de florescimento) e geada no fim do florescimento (E4, 80 a 100\% de florescimento), com três repetições. Após a aclimatação, as plantas dos tratamentos E1, E2, E3 e E4 foram submetidas à simulação de geada, em que, enquanto um dos tratamentos recebia a geada, os demais permaneciam em aclimatação, juntamente com o A0. No dia seguinte à geada, as plantas retornaram à aclimatação e, posteriormente, foram transferidas para a casa de vegetação até que o próximo tratamento atingisse $o$ desenvolvimento necessário. O ciclo térmico de geada utilizado foi idêntico ao do experimento 1 .

No experimento 4, foram simuladas intensidades de geada, em diferentes estádios iniciais do ciclo de desenvolvimento das plantas, em que elas foram submetidas a diferentes regimes de aclimatação. Os tratamentos consistiram dos genótipos Hyola 401 (precoce) e Hyola 61 (tardio), cinco estádios de desenvolvimento de planta $(4,10,15,20$ e 30 dias após a emergência, DAE), com, aproximadamente, 2, 3, 4, 5 e 6 folhas emitidas, respectivamente, e cinco regimes de aclimatação: apenas aclimatação (A0), aclimatação antes e após a simulação da geada (A1), aclimatação antes da geada (A2), aclimatação após a geada (A3) e sem aclimatação antes e após a geada (A4), com três repetições. As diferentes intensidades de geada leve, moderada, moderadamente forte e forte, a $0,-2$, -4 e $-6^{\circ} \mathrm{C}$, respectivamente - não foram consideradas tratamentos, em razão da disponibilidade de apenas uma câmara de crescimento adaptada para reproduzir temperaturas abaixo de $0^{\circ} \mathrm{C}$. Isso determinou que as geadas fossem simuladas em tempos distintos, de maneira que as plantas cresceram em condições diferentes para cada geada. Assim, as intensidades de geada não puderam ser comparadas. As geadas 
foram simuladas com ciclo térmico diário de temperatura máxima do ar de $12^{\circ} \mathrm{C}$ e temperatura mínima de cada geada, tendo permanecido 1 hora na condição de temperatura mínima, e seguido os demais procedimentos dos experimentos 1, 2 e 3 . As plantas foram transferidas para as câmaras de crescimento para aclimatação e simulação das geadas, conforme cada tratamento, e novamente transferidas para a casa de vegetação. Cada geada foi simulada uma única vez. Em razão disto, adotouse a estratégia de semeaduras escalonadas, a fim de que todos os estádios de desenvolvimento das plantas coincidissem no momento de simulação da respectiva geada. Por exemplo, no tratamento com plantas com 30 DAE, a canola foi semeada 34 dias antes da data prevista da geada.

O experimento 5 simulou a ocorrência de geadas consecutivas, em diferentes estádios de desenvolvimento das plantas, e foi conduzido em câmara de crescimento com temperatura e umidade relativa média do ar entre $18^{\circ} \mathrm{C}$ (noite) e $24^{\circ} \mathrm{C}$ (dia) e entre $50 \%$ (dia) e $100 \%$ (noite), respectivamente. Os tratamentos foram os genótipos Hyola 401 e Hyola 61, cinco estádios de desenvolvimento $(4,10$, 15,20 e 30 DAE), com aproximadamente 2, 3, 4, 5 e 6 folhas emitidas, respectivamente, e três condições de geada: sem geada (apenas aclimatação), duas geadas e três geadas consecutivas, com três repetições. Para duas geadas, as temperaturas foram -4 e $-2^{\circ} \mathrm{C}$ e, para três geadas, foram $-2,-4$ e $0^{\circ} \mathrm{C}$, simuladas em dois e três dias consecutivos, respectivamente. As condições de geada e as respectivas temperaturas do ar foram definidas em estudo da climatologia das geadas locais (Silva et al., 2008). Adotou-se a semeadura escalonada, conforme o experimento 4 .

Foram feitas avaliações quanto à queima de folhas e quantificação da massa de matéria seca da parte aérea (MS), exceto no experimento 5, em que foi avaliada apenas a MS. A queima de folhas foi avaliada aos 7 (Q7) e 15 (Q15) dias após a geada (DAG), pela atribuição de notas por observação visual de três pessoas. As notas, em cada vaso, variaram entre $1 \mathrm{e}$ 5: 1, 0-20\%; 2, 20-40\%; 3, 40-60\%; 4, 60-80\%; e $5,80-100 \%$ de queima de folhas (Silva et al., 2008). A nota final foi a média das duas notas mais próximas. A MS das plantas foi determinada aos 30 DAG, nos experimentos 1 e 2, e aos 15 DAG, nos experimentos 4 e 5 . O material vegetal foi seco em estufa a $65^{\circ} \mathrm{C}$, até massa constante, e depois pesado em balança de precisão. No experimento 3 , foram medidas as variáveis: subperíodo emergência-floração, estatura final de plantas, número de síliquas por planta, número de grãos por síliqua, peso de mil grãos e produção de grãos por vaso. $\mathrm{O}$ subperíodo emergência-floração correspondeu ao número de dias entre $50 \%$ das plantas emergidas e $50 \%$ das plantas com, pelo menos, uma flor aberta. A estatura final de plantas foi medida com régua, na haste principal. Foi contado o número de síliquas, e o número de grãos por síliqua foi estimado a partir de amostragens aleatórias de 50 síliquas. A produção de grãos por vaso foi calculada para o teor de umidade de $13 \%$.

Os dados de Q7 e Q15 foram resumidos e apresentados na forma percentual. Os demais dados foram transformados para $(\mathrm{y}+0,5)^{0,5}$, quando os desvios não seguiram a distribuição normal e as variâncias não foram constantes, tendo-se aplicado, posteriormente, a análise de variância seguida da comparação das médias, pelo teste de Tukey, a 5\% de probabilidade.

\section{Resultados e Discussão}

No experimento 1, não houve interação significativa entre os tratamentos, tanto em Q7 quanto em Q15. Verificou-se menor queima de folhas por geada nas plantas aclimatadas, em comparação às não aclimatadas, em Q7 (Tabela 1). Os genótipos Hyola 420 e Hyola 60 não apresentaram queima de folhas quando aclimatados, enquanto o Hyola 43 apresentou a maior queima de folhas, entre todos avaliados neste experimento. Aos 15 DAG, as plantas aclimatadas mostraram recuperação completa dos danos nas folhas, independentemente do genótipo, enquanto as não aclimatadas ainda apresentavam danos foliares elevados. O genótipo Hyola 401 foi o que apresentou maior velocidade de recuperação dos danos foliares quando não aclimatado, provavelmente por ser o mais precoce, cuja velocidade dos processos de crescimento e desenvolvimento é mais rápida. Esses resultados estão de acordo com os presentes na literatura, em que a aclimatação torna a canola mais tolerante à geada e possibilita a minimização dos danos foliares causados pelo frio (Rapacz, 1999; Smallwood \& Bowles, 2002; Gusta et al., 2004; Asghari et al., 2008; Stavang et al., 2008). 
Com relação à intensidade da geada (experimento 2), a queima de folhas não foi diferente entre os genótipos, em Q7 e Q15 (Tabela 1). Na geada de $-6^{\circ} \mathrm{C}$, os genótipos Hyola 401, Hyola 420 e Hyola 60 apresentaram queima completa (100\%) das folhas em Q7, enquanto as plantas do Hyola 43 e Hyola 61 apresentaram danos menores (87\%). Em Q15, na geada de $-3^{\circ} \mathrm{C}$, as plantas recuperaram completamente os danos que estavam aparentes em Q7, enquanto que, com a geada de $-6^{\circ} \mathrm{C}$, as plantas não se recuperaram em relação a Q7. Isso indica que temperatura do ar próxima a $-6^{\circ} \mathrm{C}$, ao nível do solo, pode ser letal para a canola com três folhas ou, pelo menos, causar danos significativos para a cultura se esta não passar por aclimatação anterior à geada. Esses resultados são similares aos relatados por Thomas (2003) e Gusta et al. (2004).

Tabela 1. Percentagem de queima de folhas, aos 7 (Q7) e 15 dias (Q15) após a simulação de geada $\left(-4^{\circ} \mathrm{C}\right)$, com e sem aclimatação prévia das plantas (experimento 1), e simulação de quatro intensidades de geada (sem aclimatação), em cinco híbridos de canola (experimento 2), no estádio de desenvolvimento de plantas com três folhas ${ }^{(1)}$.

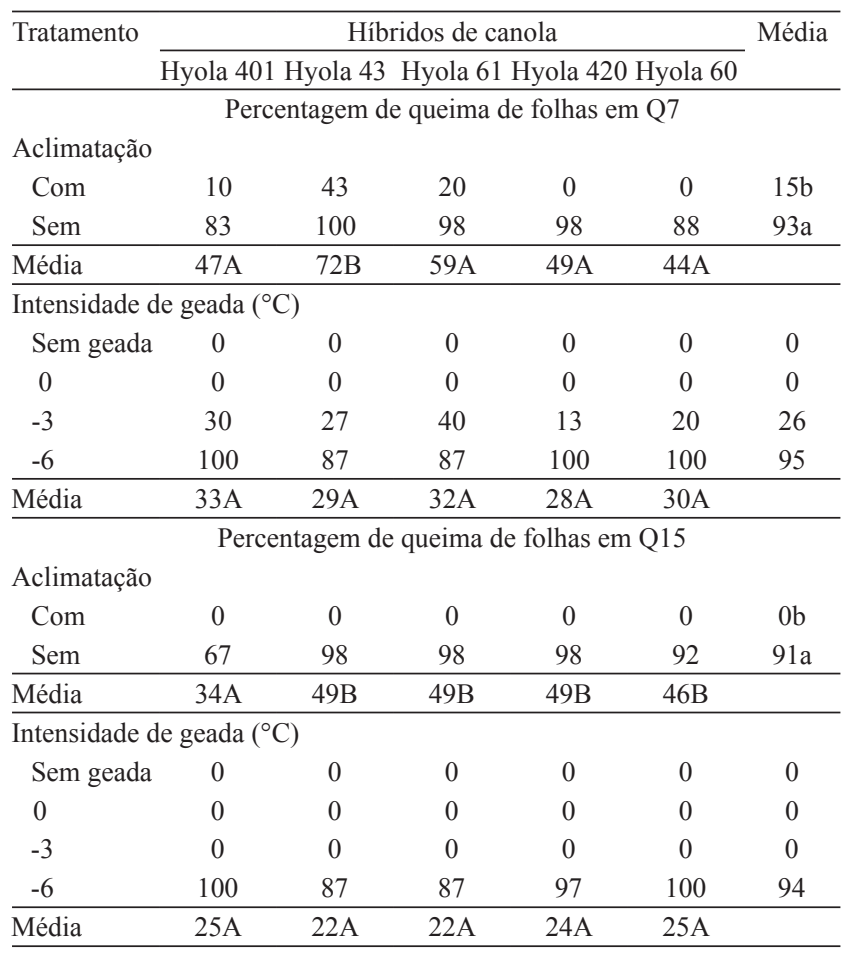

${ }^{(1)}$ Médias seguidas de letras iguais, maiúsculas nas linhas e minúsculas nas colunas, em cada tratamento, não diferem entre si pelo teste de Tukey, a $5 \%$ de probabilidade.
No que se refere à massa de matéria seca, não houve interação entre tratamentos de aclimatação e genótipos e nem entre geada e genótipos (Tabela 2). No experimento 1, as plantas aclimatadas produziram mais MS, em comparação às não aclimatadas, o que está de acordo com a menor queima de folhas observada com a aclimatação (Tabela 1). Isso confirma que a aclimatação torna a canola mais tolerante à geada e possibilita minimizar o dano causado pelo frio, conforme verificado em estudos com canola, em outros países, (Rapacz, 1999; Gusta et al., 2004; Stavang et al., 2008). Entre os genótipos, o Hyola 43 teve a menor produção de MS e apresentou maior queima de folhas. Assim, é possível afirmar que há diferença entre genótipos quanto à tolerância à geada, conforme já frisado por Rapacz (1999).

$\mathrm{Na}$ geada de $-6^{\circ} \mathrm{C}$, a MS foi menor do que nas demais intensidades, que não apresentaram diferença significativa em comparação ao tratamento sem geada (Tabela 2). Isso mostra que, apesar da ocorrência de queima de folhas a partir da intensidade de $-3^{\circ} \mathrm{C}$, a canola conseguiu recuperar a área foliar e produziu MS de forma semelhante à condição sem geada, o que está de acordo com os dados apresentados na Tabela 1 . No experimento 2, não houve diferença significativa na MS entre genótipos, porque a coleta da MS foi realizada aos $30 \mathrm{DAG}$, o que pode ter permitido a recuperação plena do crescimento das plantas submetidas a temperaturas superiores a $-6^{\circ} \mathrm{C}$.

No experimento 3, a interação entre tratamentos foi significativa para as variáveis subperíodo emergênciafloração, estatura de plantas, síliquas por planta e produção de grãos por vaso, e não significativa para as demais variáveis (Tabela 3). Em todos os genótipos, praticamente não houve efeito do estádio de desenvolvimento em que ocorre a geada sobre o tempo transcorrido entre a emergência e a floração, o que indica que o componente genético é o principal fator de definição desta variável. Porém, nos diferentes tratamentos verificou-se que, quando a geada ocorre no início do crescimento (E1), as respostas entre genótipos têm suas diferenças acentuadas (Tabela 3).

Quanto à estatura de plantas, a época de ocorrência da geada teve efeito apenas sobre o genótipo Hyola 401, especialmente em E4 (Tabela 3). Essa resposta não era esperada, já que a geada em E4 foi simulada, praticamente, ao final da floração, quando o tamanho das plantas já está definido. Assim, pode ter 
havido danos à haste principal e, com isso, a estatura foi menor do que a real. Essa explicação também se aplica a E3, que apresentou as maiores diferenças e maiores variabilidades de estatura entre genótipos. No início do florescimento (E3), as plantas estão mais predispostas a danos, pois este é o momento de ocorrência de processos mais sensíveis à geada (Lardon \& Triboi-Blondel, 1995).

Com relação ao número de síliquas por planta, apenas o Hyola 401 e o Hyola 420 apresentaram diferenças entre as épocas de ocorrência das geadas (Tabela 3). No Hyola 401, a redução foi mais significativa em E4, no Hyola 420 a maior redução ocorreu em E1. Entre genótipos, os mais precoces (Hyola 401, Hyola 43 e Hyola 420) ou de ciclo médio (Hyola 61) estiveram entre os que apresentaram maior número de síliquas, independentemente da época de ocorrência da geada, enquanto que o Hyola 60 (de ciclo mais longo) não figurou entre os que apresentaram maior número de síliquas em nenhuma época.

Com relação ao número de grãos por síliqua, ocorreram diferenças entre genótipos e entre as épocas de ocorrência das geadas (Tabela 3). O genótipo Hyola 60 teve menor número de grãos e, por consequência, seus grãos foram mais pesados, conforme mostra o maior peso de mil grãos deste genótipo. O maior número de grãos por síliqua foi apresentado pelos genótipos de ciclo mais precoce, especialmente Hyola 401 e Hyola 420. A ocorrência da geada em E3 e E4 resultou nas menores quantidades de grãos por síliqua, mas as épocas de geada não tiveram efeito sobre o peso de mil grãos.
Os Hyola 61 e Hyola 60 não sofreram efeitos da época de ocorrência da geada sobre a produção de grãos (Tabela 3). Em Hyola 401, os efeitos foram mais brandos antes do florescimento, e se acentuaram a partir daí, enquanto que em Hyola 43, a geada somente teve efeito no pleno florescimento. No genótipo Hyola 420, a maior produtividade foi observada em E2, que não diferiu de A0. Os genótipos Hyola 420, Hyola 43 e Hyola 61 estiveram entre os mais produtivos, independente da época de ocorrência da geada, enquanto que o Hyola 60 não figurou entre os mais produtivos em nenhuma época.

No experimento 4, houve interação significativa entre os tratamentos. A queima de folhas começou a ocorrer a partir da geada a $-2^{\circ} \mathrm{C}$, e o dano aumentou progressivamente até a geada a $-6^{\circ} \mathrm{C}$, nos tratamentos A3 e A4 (Tabela 4). Nesses dois tratamentos de aclimatação, a queima de folhas foi completa na geada de $-6^{\circ} \mathrm{C}$, em ambos os genótipos avaliados e em todos os estádios de desenvolvimento, enquanto em A1 e A2 praticamente não houve diferença do tratamento A0, exceto no estádio de quatro dias, quando os danos foram um pouco mais pronunciados nesses regimes em relação ao A0. A aclimatação por três dias, anteriormente à geada (Rife \& Zeinali, 2003), foi mais eficiente no aumento da tolerância ao frio do que a aclimatação após a geada, em razão de a aclimatação anterior à geada preparar a planta sob o ponto de vista morfológico, fisiológico, bioquímico e molecular, para resistir ao congelamento e à desidratação pela

Tabela 2. Massa de matéria seca da parte aérea (gramas por vaso), de plantas de cinco híbridos de canola submetidas à simulação de geada $\left(-4^{\circ} \mathrm{C}\right)$, com e sem aclimatação prévia das plantas (experimento 1), e submetidas à simulação de quatro intensidades de geada (sem aclimatação) (experimento 2), no estádio de desenvolvimento de plantas com três folhas ${ }^{(1)}$.

\begin{tabular}{|c|c|c|c|c|c|c|}
\hline \multirow[t]{2}{*}{ Tratamento } & \multicolumn{5}{|c|}{ Híbridos de canola } & \multirow[t]{2}{*}{ Média } \\
\hline & Hyola 401 & Hyola 43 & Hyola 61 & Hyola 420 & Hyola 60 & \\
\hline \multicolumn{7}{|l|}{ Aclimatação } \\
\hline Com & 1,203 & 0,977 & 1,163 & 1,070 & 1,277 & $1,138 \mathrm{a}$ \\
\hline Sem & 0,365 & 0,060 & 0,125 & 0,085 & 0,195 & $0,166 \mathrm{~b}$ \\
\hline Média & $0,784 \mathrm{~A}$ & $0,518 \mathrm{~B}$ & $0,644 \mathrm{~A}$ & $0,578 \mathrm{~A}$ & $0,736 \mathrm{~A}$ & \\
\hline \multicolumn{7}{|c|}{ Intensidade de geada $\left({ }^{\circ} \mathrm{C}\right)$} \\
\hline Sem geada & 1,210 & 1,443 & 1,287 & 1,307 & 1,513 & $1,352 \mathrm{a}$ \\
\hline 0 & 1,337 & 1,430 & 1,497 & 1,733 & 1,297 & $1,459 \mathrm{a}$ \\
\hline-3 & 1,283 & 1,007 & 0,993 & 1,443 & 1,217 & $1,189 \mathrm{a}$ \\
\hline-6 & 0,000 & 0,420 & 0,317 & 0,340 & 0,000 & $0,215 b$ \\
\hline Média & $0,958 \mathrm{~A}$ & $1,075 \mathrm{~A}$ & $1,023 \mathrm{~A}$ & $1,206 \mathrm{~A}$ & $1,007 \mathrm{~A}$ & \\
\hline
\end{tabular}

Pesq. agropec. bras., Brasília, v.45, n.9, p.933-943, set. 2010 
geada (Hawkins et al., 2002; Smallwood \& Bowles, 2002; Gusta et al., 2004; Asghari et al., 2008; Stavang et al., 2008).
Nas geadas de -2 e $-4^{\circ} \mathrm{C}$ em $\mathrm{A} 3$ e $\mathrm{A} 4$, e na geada a $-6^{\circ} \mathrm{C}$ em A2 (Tabela 4), a queima de folhas foi maior nos estádios de duas e três folhas (quatro dias), em

Tabela 3. Número de dias entre a emergência e a floração, estatura de plantas, número de síliquas por plantas, número de grãos por síliqua e rendimento de grãos para cinco cultivares de canola, em diferentes épocas de ocorrência da geada $(\text { experimento } 3)^{(1)}$.

\begin{tabular}{|c|c|c|c|c|c|c|}
\hline \multirow[t]{2}{*}{ Tratamento } & \multicolumn{5}{|c|}{ Híbridos de canola } & \multirow[t]{2}{*}{ Média } \\
\hline & Hyola 401 & Hyola 43 & Hyola 61 & Hyola 420 & Hyola 60 & \\
\hline \multicolumn{7}{|c|}{ Emergência-floração (dias) } \\
\hline A0 & $77,7 \mathrm{Ca}$ & $81,5 \mathrm{Ca}$ & $90,7 \mathrm{Ba}$ & $88,5 \mathrm{Ba}$ & $98,0 \mathrm{Aa}$ & 87,3 \\
\hline E1 & $79,8 \mathrm{Da}$ & $83,2 \mathrm{CDa}$ & $87,7 \mathrm{BCa}$ & $91,3 \mathrm{Ba}$ & $98,7 \mathrm{Aa}$ & 88,1 \\
\hline E2 & $77,8 \mathrm{Ca}$ & $80,5 \mathrm{Ca}$ & $92,2 \mathrm{ABa}$ & $87,8 \mathrm{Ba}$ & $97,3 \mathrm{Aa}$ & 87,1 \\
\hline E3 & $79,0 \mathrm{Ca}$ & $83,7 \mathrm{Ca}$ & $91,2 \mathrm{Ba}$ & $90,8 \mathrm{Ba}$ & $100,3 \mathrm{Aa}$ & 89,0 \\
\hline E4 & $81,5 \mathrm{Ba}$ & $83,3 \mathrm{ABa}$ & $93,5 \mathrm{Aa}$ & $93,3 \mathrm{Aa}$ & $94,3 \mathrm{Ab}$ & 89,2 \\
\hline Média & 79,2 & 82,4 & 91,0 & 90,4 & 97,7 & 88,1 \\
\hline \multicolumn{7}{|c|}{ Estatura de plantas $(\mathrm{cm})$} \\
\hline A0 & $121,4 \mathrm{Ba}$ & $132,6 \mathrm{ABa}$ & $130,5 \mathrm{ABa}$ & $132,1 \mathrm{ABa}$ & $150,6 \mathrm{Aa}$ & 133,4 \\
\hline E1 & $127,9 \mathrm{Ba}$ & $120,2 \mathrm{Ba}$ & $127,2 \mathrm{Ba}$ & $128,2 \mathrm{Ba}$ & $155,6 \mathrm{Aa}$ & 131,8 \\
\hline E2 & $115,5 \mathrm{Aab}$ & $137,6 \mathrm{Aa}$ & $117,5 \mathrm{Aa}$ & $136,3 \mathrm{Aa}$ & $138,3 \mathrm{Aa}$ & 129,0 \\
\hline E3 & $105,7 \mathrm{Cab}$ & $115,1 \mathrm{BCa}$ & $122,7 \mathrm{ABCa}$ & $138,7 \mathrm{ABa}$ & $143,0 \mathrm{Aa}$ & 125,0 \\
\hline E4 & $91,7 \mathrm{Bb}$ & $123,8 \mathrm{Aa}$ & $118,3 \mathrm{ABa}$ & $143,1 \mathrm{Aa}$ & $140,5 \mathrm{Aa}$ & 123,5 \\
\hline Média & 112,4 & 125,9 & 123,2 & 135,7 & 145,6 & 128,6 \\
\hline \multicolumn{7}{|c|}{ Número de síliquas por planta } \\
\hline A0 & $241,3 \mathrm{ABa}$ & $282,7 \mathrm{Aa}$ & $209,3 \mathrm{ABa}$ & $253,0 \mathrm{ABab}$ & $142,7 \mathrm{Ba}$ & 225,8 \\
\hline E1 & $223,0 \mathrm{Aab}$ & $233,3 \mathrm{Aa}$ & $239,7 \mathrm{Aa}$ & $145,3 \mathrm{ABb}$ & $83,0 \mathrm{Ba}$ & 184,9 \\
\hline E2 & $185,0 \mathrm{ABab}$ & $284,7 \mathrm{Aa}$ & $205,3 \mathrm{ABa}$ & $276,0 \mathrm{Aa}$ & $139,3 \mathrm{Ba}$ & 218,1 \\
\hline E3 & $139,0 \mathrm{BCab}$ & $199,0 \mathrm{ABCa}$ & $283,7 \mathrm{Aa}$ & $261,3 \mathrm{ABab}$ & $127,3 \mathrm{Ca}$ & 202,1 \\
\hline$\underline{\mathrm{E} 4}$ & $98,3 \mathrm{Bb}$ & $179,0 \mathrm{ABa}$ & $183,7 \mathrm{ABa}$ & $236,0 \mathrm{Aab}$ & $72,3 \mathrm{Ba}$ & 153,9 \\
\hline Média & 177,3 & 235,7 & 224,3 & 234,3 & 112,9 & 196,9 \\
\hline \multicolumn{7}{|c|}{ Número de grãos por síliqua } \\
\hline A0 & 12,3 & 9,2 & 9,7 & 13,4 & 5,7 & $10,1 \mathrm{a}$ \\
\hline E1 & 13,5 & 9,1 & 9,9 & 10,9 & 5,0 & $9,7 \mathrm{ab}$ \\
\hline E2 & 12,8 & 9,7 & 12,7 & 14,3 & 6,6 & $11,2 \mathrm{a}$ \\
\hline E3 & 8,7 & 9,2 & 6,7 & 7,4 & 4,9 & $7,4 \mathrm{bc}$ \\
\hline E4 & 8,0 & 6,1 & 4,9 & 7,7 & 2,5 & $5,8 \mathrm{c}$ \\
\hline Média & $11,0 \mathrm{~A}$ & $8,7 \mathrm{~A}$ & $8,8 \mathrm{~A}$ & $10,8 \mathrm{~A}$ & $4,9 \mathrm{~B}$ & 8,8 \\
\hline \multicolumn{7}{|c|}{ Peso de mil grãos (g) } \\
\hline A0 & 3,4 & 2,8 & 3,4 & 2,8 & 4,6 & $3,4 \mathrm{a}$ \\
\hline E1 & 3,6 & 3,3 & 3,4 & 3,3 & 4,3 & $3,6 \mathrm{a}$ \\
\hline E2 & 3,6 & 3,1 & 3,0 & 2,9 & 4,0 & $3,3 \mathrm{a}$ \\
\hline E3 & 4,0 & 3,3 & 3,8 & 3,7 & 3,8 & $3,7 \mathrm{a}$ \\
\hline $\mathrm{E} 4$ & 3,7 & 3,2 & 4,1 & 4,0 & 4,4 & $3,9 \mathrm{a}$ \\
\hline Média & $3,7 \mathrm{AB}$ & $3,1 \mathrm{~B}$ & $3,5 \mathrm{~B}$ & $3,3 \mathrm{~B}$ & $4,2 \mathrm{~A}$ & $3,6 \mathrm{a}$ \\
\hline \multicolumn{7}{|c|}{ Produção de grãos por vaso $(\mathrm{g})$} \\
\hline A0 & $10,0 \mathrm{Aa}$ & $7,2 \mathrm{ABab}$ & $6,8 \mathrm{ABa}$ & $9,6 \mathrm{Aab}$ & $3,7 \mathrm{Ba}$ & 7,5 \\
\hline E1 & $10,3 \mathrm{Aa}$ & $7,0 \mathrm{ABab}$ & $8,0 \mathrm{ABa}$ & $5,1 \mathrm{BCb}$ & $1,8 \mathrm{Ca}$ & 6,4 \\
\hline E2 & $8,4 \mathrm{Aab}$ & $8,2 \mathrm{Aa}$ & $7,3 \mathrm{ABa}$ & $11,3 \mathrm{Aa}$ & $3,7 \mathrm{Ba}$ & 7,8 \\
\hline E3 & $4,8 \mathrm{ABbc}$ & $6,0 \mathrm{ABab}$ & $7,2 \mathrm{Aa}$ & $6,6 \mathrm{Ab}$ & $1,9 \mathrm{Ba}$ & 5,3 \\
\hline E4 & $2,8 \mathrm{Abc}$ & $3,5 \mathrm{ABb}$ & $4,0 \mathrm{ABa}$ & 7,1Aab & $0,8 \mathrm{Ba}$ & 3,6 \\
\hline Média & 7,3 & 6,4 & 6,7 & 7,9 & 2,4 & 6,1 \\
\hline
\end{tabular}

${ }^{(1)}$ Médias seguidas de letras iguais, maiúsculas nas linhas e minúsculas nas colunas, não diferem entre si, pelo teste de Tukey, a $5 \%$ de probabilidade. A0, apenas aclimatação; E1, geada no início do crescimento (três folhas); E2, geada no período vegetativo (cinco a seis folhas); E3, geada no início do florescimento ( $50 \%$ de florescimento) e E4, geada no fim do florescimento ( 80 a $100 \%$ de florescimento). 
razão de o teor de água ter sido mais elevado nas plantas (Gusta et al., 2004; Silva et al., 2008) e em consequência da menor área foliar, em relação aos demais estádios. A partir de 15 DAE, os danos pela geada foram menores do que nos estádios anteriores e alcançaram o nível mínimo aos 30 DAE, quando, praticamente, não se observaram danos foliares em geadas com temperaturas do ar superiores a $-6^{\circ} \mathrm{C}$, independentemente da aclimatação.

Com relação à MS (experimento 4), houve interação entre aclimatação e estádio de desenvolvimento das plantas, para todas as geadas, e efeito simples para genótipos, exceto na geada de $-6^{\circ} \mathrm{C}$, em que também a interação foi significativa entre aclimatação e genótipos (Tabela 5). As maiores diferenças entre tratamentos de aclimatação foram observadas nas geadas de $0,-2$ e $-6^{\circ} \mathrm{C}$, nos estádios de 4 DAE e 10 DAE. O reflexo da maior queima de folhas resultou em menor MS, o que mostra relação direta entre área foliar e fotossíntese.

No tratamento com geada a $-6^{\circ} \mathrm{C}$, a diferença foi significativa na MS em A3 e A4, em comparação aos demais, pelo fato de ter ocorrido morte das plantas pela geada em todos os estádios (Tabela 5). Tal qual verificado para a queima de folhas, a falta de aclimatação antes da geada induziu a morte de plantas, especialmente sob geada forte. Conforme apresentado por Gusta et al. (2004), as folhas de canola não aclimatadas mantêm maior teor de água, o que favorece a formação de cristais de gelo entre as células, e estes podem danificar mecanicamente as células ou provocar a desidratação e o colapso total delas (Rajashekar \& Burke, 1996).

Na geada de $-4^{\circ} \mathrm{C}$ (Tabela 5), praticamente não houve diferença na MS entre tratamentos de aclimatação, nos estádios avaliados, e dos tratamentos de aclimatação

Tabela 4. Percentagem de queima de folhas, aos 7 (Q7) e 15 dias (Q15) após a simulação da geada, em cinco diferentes regimes de aclimatação (A0 a A4) ${ }^{(1)}$ e cinco estádios de desenvolvimento de plantas (dias após a emergência, DAE) de dois híbridos de canola, submetidos a quatro diferentes intensidades de geada (experimento 4$)^{(2)}$.

\begin{tabular}{|c|c|c|c|c|c|c|c|c|c|c|c|c|c|c|c|c|c|c|c|c|}
\hline \multirow[t]{3}{*}{ Aclimatação } & \multicolumn{10}{|c|}{ Hyola 401} & \multicolumn{10}{|c|}{ Hyola 61} \\
\hline & \multicolumn{2}{|c|}{$04 \mathrm{DAE}$} & \multicolumn{2}{|c|}{$10 \mathrm{DAE}$} & \multicolumn{2}{|c|}{$15 \mathrm{DAE}$} & \multicolumn{2}{|c|}{$20 \mathrm{DAE}$} & \multicolumn{2}{|c|}{$30 \mathrm{DAE}$} & \multicolumn{2}{|c|}{$04 \mathrm{DAE}$} & \multicolumn{2}{|c|}{$10 \mathrm{DAE}$} & \multicolumn{2}{|c|}{$15 \mathrm{DAE}$} & \multicolumn{2}{|c|}{$20 \mathrm{DAE}$} & \multicolumn{2}{|c|}{$30 \mathrm{DAE}$} \\
\hline & Q7 & Q15 & Q7 & Q15 & Q7 & Q15 & Q7 & Q15 & Q7 & $\overline{Q 15}$ & Q7 & Q15 & Q7 & Q15 & Q7 & Q15 & Q7 & Q15 & Q7 & Q15 \\
\hline & \multicolumn{20}{|c|}{ Intensidade de geada $0^{\circ} \mathrm{C}$} \\
\hline A0 & 0 & 0 & 0 & 0 & 0 & 0 & 0 & 0 & 0 & 0 & 0 & 0 & 0 & 0 & 0 & 0 & 0 & 0 & 0 & 0 \\
\hline A1 & 0 & 0 & 0 & 0 & 0 & 0 & 0 & 0 & 0 & 0 & 0 & 0 & 0 & 0 & 0 & 0 & 0 & 0 & 0 & 0 \\
\hline A2 & 0 & 0 & 0 & 0 & 0 & 0 & 0 & 0 & 0 & 0 & 0 & 0 & 0 & 0 & 0 & 0 & 0 & 0 & 0 & 0 \\
\hline A3 & 0 & 0 & 0 & 0 & 0 & 0 & 0 & 0 & 0 & 0 & 0 & 0 & 0 & 0 & 0 & 0 & 0 & 0 & 0 & 0 \\
\hline \multirow[t]{2}{*}{$\mathrm{A} 4$} & 0 & 0 & 0 & 0 & 0 & 0 & 0 & 0 & 0 & 0 & 0 & 0 & 0 & 0 & 0 & 0 & 0 & 0 & 0 & 0 \\
\hline & \multicolumn{20}{|c|}{ Intensidade de geada $-2^{\circ} \mathrm{C}$} \\
\hline A0 & 0 & 0 & 0 & 0 & 0 & 0 & 0 & 0 & 0 & 0 & 0 & 0 & 0 & 0 & 0 & 0 & 0 & 0 & 0 & 0 \\
\hline A1 & 0 & 0 & 0 & 0 & 0 & 0 & 0 & 0 & 0 & 0 & 0 & 0 & 0 & 0 & 0 & 0 & 0 & 0 & 0 & 0 \\
\hline A2 & 0 & 0 & 0 & 0 & 0 & 0 & 0 & 0 & 0 & 0 & 0 & 0 & 0 & 0 & 0 & 0 & 0 & 0 & 0 & 0 \\
\hline A3 & $8 \mathrm{a}$ & $3 a$ & 0 & 0 & 0 & 0 & 0 & 0 & 0 & 0 & $2 \mathrm{~b}$ & 0 & 0 & 0 & 0 & 0 & 0 & 0 & 0 & 0 \\
\hline \multirow[t]{2}{*}{ A4 } & $5 b$ & $1 \mathrm{~b}$ & 0 & 0 & 0 & 0 & 0 & 0 & 0 & 0 & $6 \mathrm{a}$ & $1 \mathrm{a}$ & $1 \mathrm{a}$ & 0 & 0 & 0 & 0 & 0 & 0 & 0 \\
\hline & \multicolumn{20}{|c|}{ Intensidade de geada $-4^{\circ} \mathrm{C}$} \\
\hline A0 & 0 & 0 & 0 & 0 & 0 & 0 & 0 & 0 & 0 & 0 & 0 & 0 & 0 & 0 & 0 & 0 & 0 & 0 & 0 & 0 \\
\hline A1 & 0 & 0 & 0 & 0 & 0 & 0 & 0 & 0 & 0 & 0 & 0 & 0 & 0 & 0 & 0 & 0 & 0 & 0 & 0 & 0 \\
\hline A2 & 0 & 0 & 0 & 0 & 1a & 0 & 0 & 0 & 0 & 0 & 0 & 0 & 0 & 0 & 0 & 0 & 0 & 0 & 0 & 0 \\
\hline A3 & $57 \mathrm{a}$ & $48 \mathrm{a}$ & 0 & 0 & 0 & 0 & 0 & 0 & 0 & 0 & $92 \mathrm{a}$ & $86 a$ & $18 \mathrm{a}$ & $15 \mathrm{a}$ & 0 & 0 & $4 a$ & $2 a$ & 0 & 0 \\
\hline \multirow[t]{2}{*}{$\mathrm{A} 4$} & $12 \mathrm{~b}$ & $8 \mathrm{~b}$ & $1 \mathrm{a}$ & $2 \mathrm{a}$ & 0 & 0 & 0 & 0 & 0 & 0 & $20 \mathrm{~b}$ & $26 \mathrm{~b}$ & $10 \mathrm{~b}$ & $7 \mathrm{~b}$ & 0 & 0 & 0 & 0 & 0 & 0 \\
\hline & \multicolumn{20}{|c|}{ Intensidade de geada $-6^{\circ} \mathrm{C}$} \\
\hline A0 & 0 & 0 & 0 & 0 & 0 & 0 & 0 & 0 & 0 & 0 & 0 & 0 & 0 & 0 & 0 & 0 & 0 & 0 & 0 & 0 \\
\hline A1 & $1 b$ & 0 & 0 & 0 & 0 & 0 & 0 & 0 & 0 & 0 & $1 \mathrm{c}$ & 0 & $5 \mathrm{~b}$ & 0 & 0 & 0 & 0 & 0 & 10 & 0 \\
\hline A2 & $53 \mathrm{a}$ & 30 & 0 & 0 & 0 & 0 & $4 b$ & 0 & 0 & 0 & $29 b$ & $13 \mathrm{~b}$ & 0 & 0 & 0 & 0 & $2 b$ & 0 & $6 \mathrm{~b}$ & 0 \\
\hline A3 & $100 \mathrm{a}$ & $100 \mathrm{a}$ & $100 \mathrm{a}$ & $100 \mathrm{a}$ & $100 \mathrm{a}$ & $100 \mathrm{a}$ & $100 \mathrm{a}$ & $100 \mathrm{a}$ & $100 \mathrm{a}$ & $100 \mathrm{a}$ & $100 \mathrm{a}$ & $100 \mathrm{a}$ & $100 \mathrm{a}$ & $100 \mathrm{a}$ & $100 \mathrm{a}$ & $100 \mathrm{a}$ & $100 \mathrm{a}$ & $100 \mathrm{a}$ & $100 \mathrm{a}$ & $100 \mathrm{a}$ \\
\hline A4 & $100 \mathrm{a}$ & $100 \mathrm{a}$ & $100 \mathrm{a}$ & $100 \mathrm{a}$ & $100 \mathrm{a}$ & $100 \mathrm{a}$ & $100 \mathrm{a}$ & $100 \mathrm{a}$ & $99 \mathrm{a}$ & $100 \mathrm{a}$ & $100 \mathrm{a}$ & $100 \mathrm{a}$ & $100 \mathrm{a}$ & $100 \mathrm{a}$ & $100 \mathrm{a}$ & $100 \mathrm{a}$ & $100 \mathrm{a}$ & $100 \mathrm{a}$ & $100 \mathrm{a}$ & $100 \mathrm{a}$ \\
\hline
\end{tabular}

${ }^{(1)} \mathrm{A} 0$, sem simulação de geada; A1, aclimatação antes e após a simulação da geada; A2, aclimatação apenas antes da simulação da geada; A3, aclimatação apenas após a simulação da geada; A4, sem aclimatação, antes e após a geada. ${ }^{(2)}$ Médias seguidas de letras iguais, nas colunas, não diferem entre si, pelo teste de Tukey, a $5 \%$ de probabilidade. 
em relação ao tratamento A0. Esta resposta não era esperada, em virtude dos resultados observados nos outros tratamentos de geada, e pode ser atribuído às condições de crescimento das plantas que foram diferentes entre os tratamentos com geada, conforme pode ser observado pela menor produção de MS no tratamento A0 em relação aos demais.

Não foram observadas interações entre os regimes de aclimatação e os genótipos avaliados, no experimento 4. O genótipo Hyola 401 apresentou maior MS do que o Hyola 61 (Tabela 5). Isto pode ser explicado pela maior precocidade do Hyola 6 em comparação ao Hyola 401.
No experimento 5, a interação foi significativa entre geada e estádio de desenvolvimento de planta e efeito simples para genótipos (Tabela 6). Praticamente, não houve diferença na MS entre geadas e o tratamento sem geada, exceto no estádio de 10 DAE no qual, em duas geadas consecutivas, ocorreu menor MS do que nas demais condições. Neste estádio, o tratamento com três geadas consecutivas não diferiu do sem geada. A resposta observada pode ser explicada pelo fato de as geadas serem: leve, moderada e moderadamente forte, cujas temperaturas foram superiores a $-6^{\circ} \mathrm{C}$, valor crítico observado nos outros experimentos deste trabalho (Tabela 2).

Tabela 5. Massa da matéria seca da parte aérea (grama por vaso), em diferentes estádios de desenvolvimento das plantas (dias após a emergência de plantas, DAE), em dois híbridos de canola, submetidos a cinco regimes de aclimatação (A0 a A4) ${ }^{(1)}$ e quatro intensidades de geada (experimento 4) ${ }^{(1)}$.

\begin{tabular}{|c|c|c|c|c|c|c|c|}
\hline \multirow[t]{2}{*}{ Aclimatação } & \multicolumn{5}{|c|}{ Estádios } & \multicolumn{2}{|c|}{ Híbridos } \\
\hline & $4 \mathrm{DAE}$ & $10 \mathrm{DAE}$ & $15 \mathrm{DAE}$ & $20 \mathrm{DAE}$ & $30 \mathrm{DAE}$ & Hyola 401 & Hyola 61 \\
\hline & \multicolumn{7}{|c|}{ Intensidade de geada $0^{\circ} \mathrm{C}$} \\
\hline A0 & $0,349 \mathrm{ab}$ & $0,599 \mathrm{ab}$ & $0,995 \mathrm{a}$ & $1,685 \mathrm{a}$ & $2,377 \mathrm{a}$ & 1,212 & 1,190 \\
\hline A1 & $0,269 b$ & $0,617 \mathrm{ab}$ & $0,685 b$ & $1,536 \mathrm{a}$ & $1,960 \mathrm{a}$ & 1,105 & 0,922 \\
\hline $\mathrm{A} 2$ & $0,376 \mathrm{ab}$ & $0,535 b$ & $0,719 b$ & $1,500 \mathrm{a}$ & $2,032 \mathrm{a}$ & 1,067 & 0,953 \\
\hline A3 & $0,437 \mathrm{a}$ & $0,778 \mathrm{a}$ & $1,042 \mathrm{a}$ & $1,730 \mathrm{a}$ & $1,916 \mathrm{a}$ & 1,208 & 1,085 \\
\hline A4 & $0,425 \mathrm{a}$ & $0,655 \mathrm{ab}$ & $0,958 \mathrm{a}$ & $1,673 \mathrm{a}$ & $2,256 \mathrm{a}$ & 1,170 & 1,184 \\
\hline \multirow[t]{2}{*}{ Média } & 0,371 & 0,637 & 0,880 & 1,625 & 2,108 & $1,153 \mathrm{~A}$ & $1,067 \mathrm{~B}$ \\
\hline & \multicolumn{7}{|c|}{ Intensidade de geada $-2^{\circ} \mathrm{C}$} \\
\hline A0 & $0,191 b$ & $0,545 \mathrm{a}$ & $0,859 \mathrm{a}$ & $1,324 \mathrm{ab}$ & $2,617 \mathrm{a}$ & 1,089 & 1,125 \\
\hline A1 & $0,251 \mathrm{a}$ & $0,535 \mathrm{a}$ & $0,856 \mathrm{a}$ & $1,655 \mathrm{a}$ & $2,279 \mathrm{a}$ & 1,130 & 1,100 \\
\hline A2 & $0,204 b$ & $0,587 \mathrm{a}$ & $1,049 \mathrm{a}$ & $1,108 b$ & $2,519 \mathrm{a}$ & 1,195 & 0,992 \\
\hline A3 & $0,205 b$ & $0,489 \mathrm{a}$ & $0,934 \mathrm{a}$ & $1,350 \mathrm{ab}$ & $2,571 \mathrm{a}$ & 1,151 & 1,068 \\
\hline A4 & $0,195 b$ & $0,568 \mathrm{a}$ & $0,834 \mathrm{a}$ & $1,220 \mathrm{~b}$ & $2,468 \mathrm{a}$ & 1,061 & 0,952 \\
\hline \multirow[t]{2}{*}{ Média } & 0,209 & 0,545 & 0,906 & 1,331 & 2,491 & $1,125 \mathrm{~A}$ & $1,048 \mathrm{~B}$ \\
\hline & \multicolumn{7}{|c|}{ Intensidade de geada $-4^{\circ} \mathrm{C}$} \\
\hline A0 & $0,123 a$ & $0,246 \mathrm{a}$ & $0,644 \mathrm{a}$ & $0,910 \mathrm{a}$ & $2,005 \mathrm{a}$ & 0,774 & 0,692 \\
\hline A1 & $0,113 \mathrm{a}$ & $0,207 \mathrm{a}$ & $0,612 \mathrm{a}$ & $0,874 \mathrm{a}$ & $1,889 \mathrm{a}$ & 0,833 & 0,718 \\
\hline $\mathrm{A} 2$ & $0,119 \mathrm{a}$ & $0,167 \mathrm{a}$ & $0,711 \mathrm{a}$ & $0,805 \mathrm{a}$ & $2,075 \mathrm{a}$ & 0,683 & 0,612 \\
\hline A3 & $0,057 \mathrm{a}$ & $0,180 \mathrm{a}$ & $0,581 \mathrm{a}$ & $0,749 \mathrm{a}$ & $1,881 \mathrm{a}$ & 0,686 & 0,709 \\
\hline A4 & $0,067 \mathrm{a}$ & $0,172 \mathrm{a}$ & $0,561 \mathrm{a}$ & $0,667 \mathrm{~b}$ & $2,021 \mathrm{a}$ & 0,808 & 0,763 \\
\hline \multirow[t]{2}{*}{ Média } & 0,096 & 0,195 & 0,622 & 0,801 & 1,974 & $0,757 \mathrm{~A}$ & $0,699 \mathrm{~A}$ \\
\hline & \multicolumn{7}{|c|}{ Intensidade de geada $-6^{\circ} \mathrm{C}$} \\
\hline A0 & $0,286 a$ & $0,478 \mathrm{a}$ & $0,920 \mathrm{a}$ & $1,410 \mathrm{a}$ & $3,402 \mathrm{a}$ & $1,382 \mathrm{a}$ & $1,216 \mathrm{a}$ \\
\hline A1 & $0,175 \mathrm{ab}$ & $0,523 \mathrm{a}$ & $0,793 \mathrm{a}$ & $1,613 \mathrm{a}$ & $2,570 \mathrm{a}$ & $1,245 \mathrm{a}$ & $1,024 \mathrm{a}$ \\
\hline $\mathrm{A} 2$ & $0,115 b$ & $0,580 \mathrm{a}$ & $0,854 \mathrm{a}$ & $1,509 \mathrm{a}$ & $2,782 \mathrm{a}$ & $1,214 \mathrm{a}$ & $1,094 \mathrm{a}$ \\
\hline A 3 & $0,000 \mathrm{c}$ & $0,000 \mathrm{~b}$ & $0,000 \mathrm{~b}$ & $0,000 \mathrm{~b}$ & $0,000 \mathrm{~b}$ & $0,000 \mathrm{~b}$ & $0,000 \mathrm{~b}$ \\
\hline A4 & $0,000 \mathrm{c}$ & $0,000 \mathrm{~b}$ & $0,000 \mathrm{~b}$ & $0,000 \mathrm{~b}$ & $0,000 \mathrm{~b}$ & $0,000 \mathrm{~b}$ & $0,000 \mathrm{~b}$ \\
\hline Média & 0,115 & 0,316 & 0,513 & 0,906 & 1,751 & 0,768 & 0,667 \\
\hline
\end{tabular}

${ }^{(1)} \mathrm{A} 0$, sem simulação de geada; A1, aclimatação antes e após a simulação da geada; A2, aclimatação apenas antes da simulação da geada; A3, aclimatação apenas após a simulação da geada; A4, sem aclimatação, antes e após a geada. ${ }^{(2)}$ Médias seguidas de letras iguais, minúsculas nas colunas e maiúsculas nas linhas, não diferem entre si, pelo teste de Tukey, a 5\% de probabilidade. 
Tabela 6. Massa de matéria seca da parte aérea (grama por vaso), em diferentes estádios de desenvolvimento de plantas (dias após a emergência, DAE), em dois híbridos de canola, submetidos a três condições de geada (intensidades e dias com ocorrência de geada) (experimento 5) ${ }^{(1)}$.

\begin{tabular}{|c|c|c|c|c|c|c|c|}
\hline \multirow{2}{*}{$\begin{array}{l}\text { Condição } \\
\text { de geada }{ }^{(2)}\end{array}$} & \multicolumn{5}{|c|}{ Estádios } & \multicolumn{2}{|c|}{ Híbridos } \\
\hline & $4 \mathrm{DAE}$ & $10 \mathrm{DAE}$ & $15 \mathrm{DAE}$ & $20 \mathrm{DAE}$ & $30 \mathrm{DAE}$ & $\begin{array}{c}\text { Hyola } \\
401\end{array}$ & $\begin{array}{c}\text { Hyola } \\
61\end{array}$ \\
\hline Sem geada & $0,170 \mathrm{a}$ & $0,391 \mathrm{a}$ & $0,868 \mathrm{a}$ & $1,446 \mathrm{a}$ & $2,715 \mathrm{a}$ & 1,156 & 1,080 \\
\hline Duas geadas & $0,122 \mathrm{a}$ & $0,260 \mathrm{~b}$ & $0,731 \mathrm{a}$ & $1,288 \mathrm{a}$ & $1,972 \mathrm{a}$ & 0,914 & 0,835 \\
\hline Três geadas & $0,182 \mathrm{a}$ & $0,444 \mathrm{a}$ & $0,719 \mathrm{a}$ & $1,218 \mathrm{a}$ & $2,158 \mathrm{a}$ & 1,017 & 0,871 \\
\hline Média & 0,158 & 0,365 & 0,773 & 1,317 & 2,282 & \multicolumn{2}{|c|}{$1,029 \mathrm{~A} \quad 0,929 \mathrm{~B}$} \\
\hline
\end{tabular}

\section{Conclusões}

1. A aclimatação da canola ao frio antes da ocorrência de geada diminui os danos provocados quando a geada ocorre no início do ciclo de desenvolvimento das plantas, com menor queima de folhas e maior produção de matéria seca.

2. Geada com temperatura do ar de $-6^{\circ} \mathrm{C}$ causa a morte das plantas de canola não aclimatadas ao frio, em estádios iniciais do ciclo de desenvolvimento.

3. Dois ou três dias com geadas consecutivas, de intensidade leve, moderada e moderadamente forte, não causam danos significativos às plantas de canola aclimatadas ao frio, em estádios iniciais do ciclo de desenvolvimento.

4. A geada no período de floração da canola causa perda de rendimento de grãos pela redução do número de síliquas por planta e menor número de grãos por síliqua.

5. Genótipos de canola apresentam variabilidade de resposta à geada, principalmente nos estádios iniciais de desenvolvimento das plantas.

\section{Referências}

ASGHARI, A.; MOHAMMADI, S.A.; MOGHADDAM, M.; TOORCHI, M.; MOHAMMADINASAB, A.D. Analysis of quantitative trait loci associated with freezing tolerance in rapeseed (Brassica napus, L.). Biotechnology \& Biotecnological Equipment, v.22, p.548-552, 2008.

GUSTA, L.V.; TRISCHUK, R.; WEISER, C.J. Plant cold acclimation: the role of abscisic acid. Journal of Plant Growth Regulation, v.24, p.308-318, 2005.
GUSTA, L.V.; WISNIEWSKI, M.; NESBITT, N.T.; GUSTA, M.L. The effect of water, sugars, and proteins on the pattern of ice nucleation and propagation in acclimated and nonacclimated canola leaves. Plant Physiology, v.135, p.1642-1653, 2004.

HAWKINS, G.P.; DENG, Z.; KUBIK, T.J.; JOHNSON-FLANAGAN, A.M. Characterization of freezing tolerance and vernalization in Vern-, a spring-type Brassica napus line derived from a winter cross. Planta, v.216, p.220-226, 2002.

JINLING, M. Pollen selection for cold resistance at flowering time in Brassica napus. Cruciferae Newsletter, v.19, p.85-86, 1997.

JOHNSON-FLANAGRAN, A.M.; HUIWEN, Z.; GENG, X.; BROWN, D.C.W.; NYKIFORUK, C.L.; SINGH, J. Frost, abscisic acid, and desiccation hasten embryo development in Brassica napus. Plant Physiology, v.99, p.700-706, 1992.

LARDON, A.; TRIBOI-BLONDEL, A.M. Cold and freeze stress at flowering: effects on seed yields in winter rapeseed. Field Crops Research, v.44, p.95-101, 1995.

MCCLINCHEY, S.L.; KOTT, L.S. Production of mutants with high cold tolerance in spring canola (Brassica napus). Euphytica, v.162, p.51-67, 2008.

RAJASHEKAR, C.B.; BURKE, M.J. Freezing characteristics of rigid plant tissues. Plant Physiology, v.11, p.597-603, 1996.

RAPACZ, M. Frost resistance and cold acclimation abilities of spring-type oilseed rape. Plant Science, v.147, p.55-64, 1999.

RAPACZ, M.; TOKARZ, K.; JANOVWIAK, F. The initiation of elongation growth during long-term low-temperature stay of spring-type oilseed rape may trigger loss of frost resistance and changes in photosynthetic apparatus. Plant Science, v.161, p.221-230, 2001.

RIFE, C.L.; ZEINALI, H. Cold tolerance in oilseed rape over varying acclimation durations. Crop Science, v. 43, p.96-100, 2003.

ROBERTSON, M.J.; HOLLAND, J.F.; BAMBACH, R. Response of canola and Indian mustard to sowing data in the grain belt of Worth-Eastern Australia. Australian Journal of Experimental Agriculture, v.44, p.43-52, 2004.

ROBERTSON, M.J.; HOLLAND, J.F.; CAWLEY, S.; POTTER, T.D.; BURTON, W.; WALTON, G.H.; THOMAS, G. Growth and yield differences between triazine-tolerant and non-triazine-tolerant cultivars of canola. Australian Journal of Agricultural Research, v.53, p.643-651, 2002.

SANTOS, H.G. dos; JACOMINE, P.K.T.; ANJOS, L.H.C. dos; OLIVEIRA, V.A. de; OLIVEIRA, J.B. de; COELHO, M.R.; LUMBRERAS, J.F.; CUNHA, T.J.F. (Ed.). Sistema brasileiro de classificação de solos. 2.ed. Rio de Janeiro: Embrapa Solos, 2006. $306 \mathrm{p}$.

SILVA, E.P. da; CUNHA, G.R. da; PIRES, J.L.F.; DALMAGO, G.A.; PASINATO, A. Fatores abióticos envolvidos na tolerância de trigo à geada. Pesquisa Agropecuária Brasileira, v.43, p.1257-1265, 2008.

SMALLWOOD, M.; BOWLES, D.J. Plants in a cold climate. Philosophical Transactions of the Royal Society of London. Series B. Biological Sciences, v.357, p.831-847, 2002. 
STAVANG, J.A.; HANSEN, M.; OLSEN, J.E. Short term temperature drops do not enhance cold tolerance. Plant Growth Regulation, v.55, p.199-206, 2008.

TASSEVA, G.; VIRVILLE, J.D. de; CANTREL, C.; MOREAU, F.; ZACHOWSKI, A. Changes in the endoplasmic reticulum lipid properties in response to low temperature in Brassica napus. Plant Physiology and Biochemistry, v.42, p.811-822, 2004.
THOMAS, P. Canola grower's manual. Winnipeg: Canola Council of Canada, 2003. Disponível em: <http://www. canolacouncil.org/canola_growers_manual.aspx $>$. Acesso em: 14 maio 2007.

TOMM, G.O. Indicativos tecnológicos para a produção de canola no Rio Grande do Sul. Passo Fundo: Embrapa Trigo, 2007. 68p. (Embrapa Trigo. Sistema de produção, 4).

Recebido em 25 de janeiro de 2010 e aprovado em 1 de setembro de 2010 